\title{
Ventilation heterogeneity in children with severe asthma
}

\author{
Amy G. Nuttall ${ }^{1,2}$ (D) Caroline S. Beardsmore ${ }^{1,2} \cdot$ Erol A. Gaillard $^{1,2}$ \\ Received: 17 February 2021 / Revised: 29 April 2021 / Accepted: 2 May 2021 / Published online: 13 May 2021 \\ (C) Crown 2021
}

\begin{abstract}
Small airway disease, characterised by ventilation heterogeneity $(\mathrm{VH})$, is present in a subgroup of patients with asthma. Ventilation heterogeneity can be measured using multiple breath washout testing. Few studies have been reported in children. We studied the relationship between VH, asthma severity, and spirometry in a cross-sectional observational cohort study involving children with stable mild-moderate and severe asthma by GINA classification and a group of healthy controls. Thirty-seven participants aged 5-16 years completed multiple breath nitrogen washout (MBNW) testing (seven controls, seven mild-moderate asthma, 23 severe asthma). The lung clearance index (LCI) was normal in control and mild-moderate asthmatics. LCI was abnormal in 5/23 (21\%) of severe asthmatics. The LCI negatively correlated with $\mathrm{FEV}_{1} z$-score.

Conclusion: VH is present in asthmatic children and appears to be more common in severe asthma. The LCI was significantly higher in the cohort of children with severe asthma, despite no difference in $\mathrm{FEV}_{1}$ between the groups. This supports previous evidence that LCI is a more sensitive marker of airway disease than $\mathrm{FEV}_{1}$. MBNW shows potential as a useful tool to assess children with severe asthma and may help inform clinical decisions.
\end{abstract}

\section{What is Known:}

- Increased ventilation heterogeneity is present in some children with asthma

- Spirometry is not sensitive enough to detect small airway involvement in asthma

What is New

- Lung clearance index is abnormal in a significant subgroup of children with severe asthma but rarely in children with mild-moderate asthma - Our data suggests that LCI monitoring should be considered in children with severe asthma

Keywords Asthma $\cdot$ Spirometry $\cdot$ Lung clearance index $\cdot$ Multiple breath washout $\cdot$ Cohort study $\cdot$ Wheeze

\section{Introduction}

Communicated by Peter de Winter

Erol A. Gaillard

eag15@leicester.ac.uk

Amy G. Nuttall

amynuttall@doctors.org.uk

Caroline S. Beardsmore

csb@leicester.ac.uk

1 Department of Respiratory Sciences and Institute for Lung Health, Leicester NIHR Biomedical Research Centre - Respiratory Theme, Leicester Royal Infirmary, University of Leicester, PO Box 65, Robert Kilpatrick Clinical Sciences Building, Leicester LE2 7LX, UK

2 Department of Paediatric Respiratory Medicine, Leicester Children's Hospital, Leicester Royal Infirmary, Leicester, UK
Asthma in children is common, with most controlled with low doses of inhaled corticosteroids. A subgroup of children has more severe asthma. Ventilation heterogeneity $(\mathrm{VH})$ is well described in adults with severe asthma; however, our understanding of the contribution of small airway disease to asthma severity in children remains limited.

Knowledge of peripheral airway dysfunction may have therapeutic implications as conventional inhaled therapy may not reach the peripheral airways, an often-overlooked aspect in asthma management.

Spirometry is insensitive to disease at the level of the small airways [1]. In recent years, there has been increasing interest in multibreath washout (MBW) tests. The Lung Clearance Index (LCI), derived from MBW, is recognised as a measure of global lung function. 
Previous studies of VH in children mostly focused on cohorts with milder asthma and showed higher lung clearance index (LCI) in children with asthma compared to controls [2, 3]; however, the average LCIs were usually still within the normal range $[4,5]$. Others did not stratify by severity [5-7] or focused solely on severe asthma [8].

We aimed to investigate the presence of $\mathrm{VH}$ in asthmatic children using multiple breath nitrogen washout (MBNW), focusing on assessment of the relationships between the following: (1) LCI and asthma disease severity (represented by Global Initiative for Asthma (GINA) step scores) and (2) LCI and spirometry, primarily $\mathrm{FEV}_{1}$.

\section{Materials and methods}

This is a cross-sectional observation study in children with asthma to investigate if differences exist in $\mathrm{VH}$ between children with and without asthma, and between varying severities of asthma.

Children with physician-diagnosed asthma and control participants aged 5-16 years were recruited at Leicester Royal Infirmary, Leicester, UK. Children with stable asthma with scheduled attendances during the study period were recruited from general respiratory or asthma clinics. Control subjects with no respiratory disease were recruited from the children's diabetes clinic and also included healthy siblings. All aspects of the study were approved by the Research Ethics Committee (study numbers 12/WM/0413 and 09/H0403/92). All children attended the laboratory with a parent/guardian. We assessed asthma control using the children's asthma control test (c-ACT) for children aged 5 to 11 years and the asthma control test (ACT) in children $\geq 12$ years. Test scores $>19$ for either test indicates good current asthma control. Written informed consent was taken from all parents/guardians, with ageappropriate written consent/assent taken from all children before enrolment.

The lack of data available on MBW in children with asthma meant that we were unable to perform meaningful power calculations. The sample size was therefore opportunistic and determined by the number of participants that could be recruited by a research fellow (AN) during the study period.

Current prescribed medication information was used to classify severity of asthma as mild-moderate (steps 1-3) or severe (steps 4-5), according to the GINA step guidance (www.ginasthma.org).

\section{Lung function testing}

Spirometry was performed according to the ATS/ERS guidelines [9], using a MicroLab spirometer (Vyaire Medical Products Ltd., Basingstoke, UK).

Fractional exhaled nitric oxide (FeNO) was measured using the NIOX MINO device (Circassia Group plc, Oxford, UK), following American Thoracic Society clinical practice recommendations (Dweik RA 2011) and using a flow of $50 \pm$ $5 \mathrm{~mL} / \mathrm{s}$. FeNO $>35 \mathrm{ppb}$ was regarded as a positive test, indicating the presence of type 2 airway inflammation.

MBNW measurements were made using the EXHALYZER D with SPIROWARE 3.1.6 software package (Eco Medics, Switzerland), according to ERS/ATS criteria relating to procedure and test quality control [10]. The equipment was regularly calibrated to ensure accurate measurement. Participants completed MBNW in an upright seated position wearing nose clips. Children began by breathing medical air; then, after a steady breathing pattern was established, the EXHALYZER D automatically switched the gas to $100 \%$ oxygen and began the washout phase. The washout continued until the end-tidal concentration of $\mathrm{N}_{2}$ reached the target of less than 1/40th of initial starting concentration for three consecutive breaths. LCI values represent the number of lung volume "turnovers" required for the end-tidal concentration of $\mathrm{N}_{2}$ to reach the target. The test was repeated at least three times, with sufficient time between trials to allow subjects to re-equilibrate with room air. A minimum of two acceptable tests was required for the test to be valid and included in the analysis.

Tests where FRC differed by $>25 \%$ from the overall median were excluded. Tests were acceptable if LCI values were within $10 \%$ where three tests were completed, and within $5 \%$ if two tests were completed.

\section{Statistical analysis}

Results of FVC and $\mathrm{FEV}_{1}$ were converted to $z$-scores using the Global Lung Function Initiative Software Version 3.3.1 Build 5 to allow comparison of results. We focused primarily on $\mathrm{FEV}_{1}$ values, as this is the spirometry parameter most frequently examined in previous MBW studies.

Published reference values for MBNW were used to define normal LCI, with 7.91 representing the upper limit of normal (ULN) [11].

Non-parametric testing was used for group comparisons (Mann-Whitney and Kruskal-Wallis tests). Spearman correlation tests were used to compare relationships between variables. All analyses were performed in GraphPad Prism (V7.0, San Diego, CA, USA).

\section{Results}

Thirty-eight asthmatic children and seven controls were recruited. Thirty asthmatic children and seven controls successfully completed MBW ( $82.2 \%$ of participants) and were included in further analysis. Twenty-three were classified as severe asthma (10 male, 13 female) and seven as mildmoderate asthma ( 5 male, 2 female). There were no significant differences between the age or gender distributions of the participants in each group. 


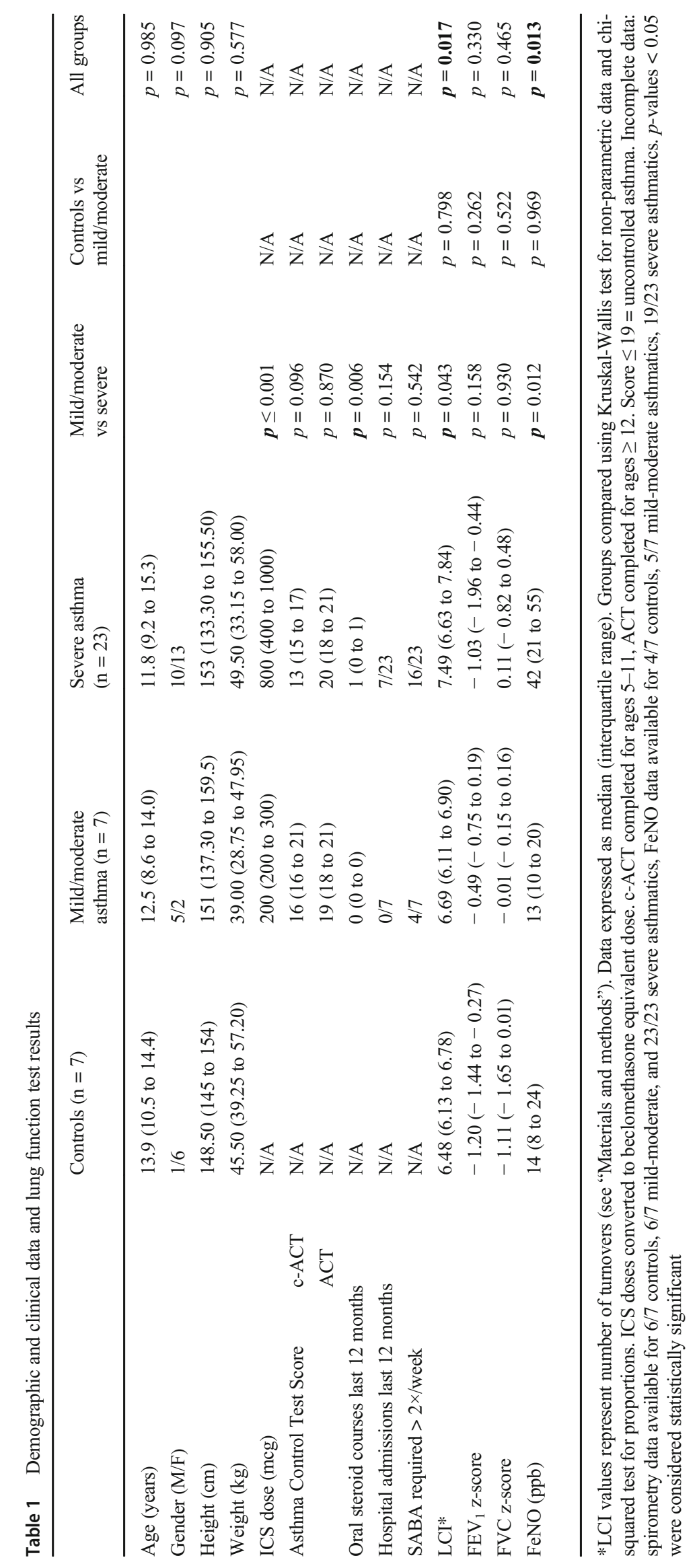


Lung function testing results for spirometry, FeNO, and MBNW are presented in Table 1.

\section{$\mathrm{LCI}$ vs disease severity}

As disease severity increased, there was an increase in LCI, with a significant difference found on comparison of all groups $(p=0.017)$. All the control participants and mildmoderate asthmatics had normal LCI (ULN 7.91). LCI of the severe asthmatics were significantly higher than those of children with mild-moderate asthma and controls (Table 1). Five out of 23 severe asthmatics had abnormal LCI, with the LCI scores of several further participants in this group near the ULN. Individual LCI data is displayed in Fig. $1 b$.

\section{LCl vs FEV}

Regarding the spirometry results, there was no significant difference between the $\mathrm{FEV}_{1} z$-score and FVC $z$ score between the groups.

There was a significant negative correlation between LCI and $\mathrm{FEV}_{1} z$-score $(r=-0.65, p \leq 0.001)$ (Fig. 1a). All participants with an abnormal $\mathrm{FEV}_{1} z$-score also had an abnormal LCI. One out of 30 asthmatic participants had normal $\mathrm{FEV}_{1} z-$ scores but abnormal LCI.

\section{LCI vs Asthma Control Score}

As defined by an ACT or c-ACT score $>19,11 / 30$ asthmatics were controlled, and 19/30 were uncontrolled. There was no significant difference between the LCI values of controlled vs uncontrolled asthmatics $(p=0.10)$.

\section{Discussion}

Small airway disease in children with asthma has been little studied. Involvement of the small airways in the disease process may be a factor in some patients with asthma who respond poorly to conventional coarse-particle inhaled corticosteroids [12]. We found that all children with mild-moderate asthma had LCI values within the normal range, with no significant difference found between LCI of this group and healthy controls. However, VH, as represented by an increase in LCI (> 7.91), was a feature in just over $20 \%$ of the children we studied with severe asthma. This finding is consistent with that of Irving et al., who demonstrated abnormal LCI in children with severe treatment-resistant asthma [8].

Previous studies in children have demonstrated increased LCIs in asthmatic children compared with controls, but results were mostly within predicted limits [5-7, 13]. Consistent with previous studies, our data in mild-moderate asthmatics demonstrated normal LCI in all these participants. Our separation of asthmatics by severity group allowed a more specific analysis of this relationship and revealed a clear difference between mild-moderate and a subgroup of severe asthmatics, whereas the previous studies focus either on asthma cohorts of mixed severity (largely mild-moderate asthma) or exclusively on severe asthma. Our identification of a subgroup of severe asthmatic children with abnormal LCI may indicate the presence of a subgroup of asthmatic children in which small airway disease is a significant feature of their asthma.

In our asthmatic cohort, we observed a strong negative correlation between LCI and $\mathrm{FEV}_{1}$. All asthmatic participants with abnormal $\mathrm{FEV}_{1} z$-scores also had abnormal LCI. This suggests that measuring LCI in addition to routine pulmonary function

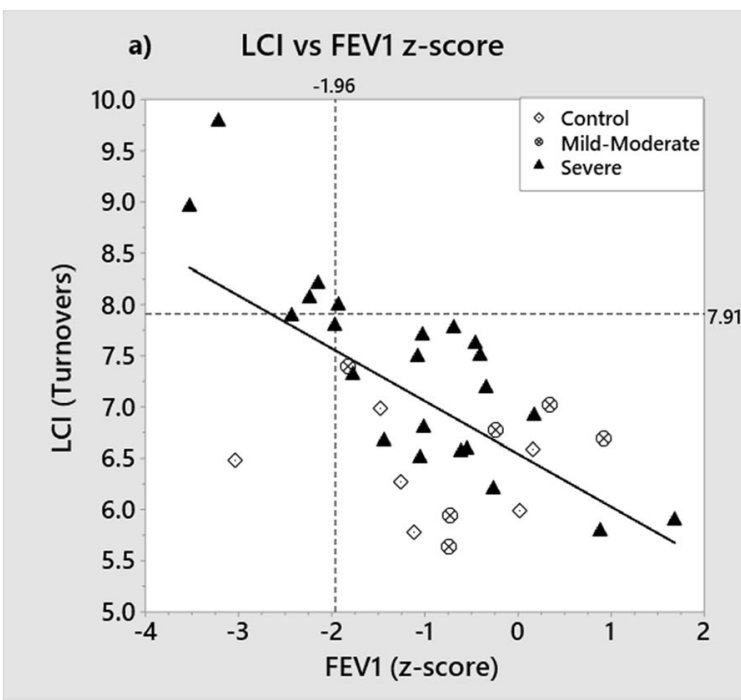

Fig. 1 LCI plotted against $\mathrm{FEV}_{1} z$-score and boxplot displaying individual LCI data. a Correlation between LCI and $\mathrm{FEV}_{1} z$-score in 29 asthmatic participants and 6 controls. Diamond - controls; circles - mildmoderate asthmatics; triangles — severe asthmatics. Horizontal dotted line

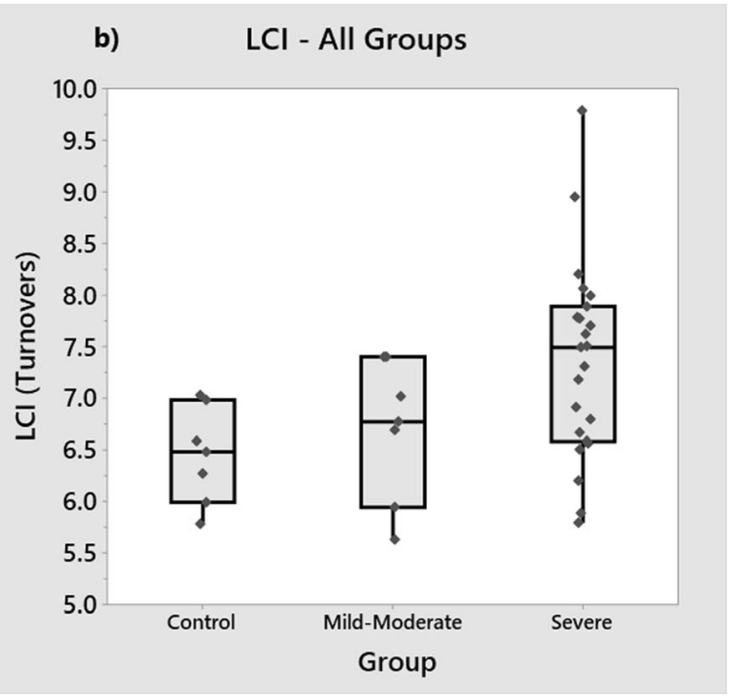

at $7.91=\mathrm{ULN}$ for LCI. Vertical dotted line at $-1.96=\mathrm{LLN}$ for $\mathrm{FEV}_{1}$. Best-fit linear regression line shown. b Boxplots displaying individual LCI data for all participants, box represents IQR with line at the median 
testing is of benefit in children with severe asthma to assess ventilation heterogeneity as a potential comorbidity in these patients.

MBNW measurements are time-consuming, and like many studies in this area, our study is limited by its relatively small sample size. Sampling was opportunistic from a cohort of asthmatic children under specialist care, which limited the number of mild-moderate asthmatics recruited. We did not have electronic monitoring data to confirm adherence to treatment, something that future studies should look to include as adherence is a major confounder in asthma studies. Within our cohort, we did not identify a significant difference in LCI between controlled and uncontrolled asthmatics (as defined by the ACT/c-ACT). Future studies focusing on children with persistently uncontrolled asthma would be of benefit to assess this relationship further.

\section{Conclusion}

Evidence demonstrating the presence of ventilation heterogeneity in childhood asthma is starting to emerge. By stratifying our cohort by asthma severity, we have demonstrated that $\mathrm{VH}$ is a particular feature of severe asthma, with abnormal LCI found in just over $20 \%$ of severe but in none of the mild-moderate asthmatics. We conclude that measuring LCI in children with severe asthma is of benefit to evaluate the presence and severity of ventilation heterogeneity in this subgroup as a potential comorbidity.

\begin{abstract}
Abbreviations c-ACT, Children's Asthma Control Test; ACT, Asthma Control Test; FeNO, Fractional exhaled nitric oxide; GINA, Global Initiative for Asthma; GLI, Global Lung Function Initiative; LCI, Lung Clearance Index; MBNW, Multiple breath nitrogen washout; MBW, Multiple breath washout; ULN, Upper limit of normal; VH, Ventilation heterogeneity
\end{abstract}

Authors' contributions AN designed the study, recruited participants, collected data, and drafted and revised the paper. CSB drafted and revised the paper. EAG drafted and revised the paper.

Data availability Original data available from the authors upon request.

Code availability N/A.

\section{Declarations}

Ethics approval Approval by the local Medical Research Ethics Committee (12/WM/0413, 09/H0403/92).

Consent to participate Written consent obtained from all participants/ guardians of participants.
Consent for publication Written consent obtained from all participants/ guardians of participants for publication of data. All authors consent to publication.

Conflict of interest Dr. Nuttall-no conflicts of interest. Dr. Beardsmore - no conflicts of interest. Dr. Gaillard reports consultancy work for Boehringer Ingelheim with money paid to the institution (University of Leicester). Investigator led research grant from Circassia, Gilead, and Chiesi Ltd. Research collaboration with MedImmune. No sponsorship was received for this research.

Open Access This article is licensed under a Creative Commons Attribution 4.0 International License, which permits use, sharing, adaptation, distribution and reproduction in any medium or format, as long as you give appropriate credit to the original author(s) and the source, provide a link to the Creative Commons licence, and indicate if changes were made. The images or other third party material in this article are included in the article's Creative Commons licence, unless indicated otherwise in a credit line to the material. If material is not included in the article's Creative Commons licence and your intended use is not permitted by statutory regulation or exceeds the permitted use, you will need to obtain permission directly from the copyright holder. To view a copy of this licence, visit http://creativecommons.org/licenses/by/4.0/.

\section{References}

1. Verbanck S (2012) Physiological measurement of the small airways. Respiration. 84(3):177-188

2. Nuttall AGL, Velasquez W, Beardsmore CS, Gaillard EA (2019) Lung clearance index: assessment and utility in children with asthma. Eur Respir Rev 28(154). https://doi.org/10.1183/16000617. 0046-2019 Print 2019 Dec 31

3. Knihtila H, Kotaniemi-Syrjanen A, Pelkonen AS, Makela MJ, Malmberg LP (2018) Small airway function in children with mild to moderate asthmatic symptoms. Ann Allergy Asthma Immunol 121(4):451-457

4. de Gouveia Belinelo P, Nielsen A, Goddard B, Platt L, Sena DS, Rebeca C, Robinson PD et al (2020) Clinical and lung function outcomes in a cohort of children with severe asthma. BMC Pulm Med 20(1):66

5. Macleod KA, Horsley AR, Bell NJ, Greening AP, Innes JA, Cunningham S (2009) Ventilation heterogeneity in children with well controlled asthma with normal spirometry indicates residual airways disease. Thorax. 64(1):33-37

6. Zwitserloot A, Fuchs SI, Muller C, Bisdorf K, Gappa M (2014) Clinical application of inert gas multiple breath washout in children and adolescents with asthma. Respir Med 108(9):1254-1259

7. Racette C, Lu Z, Kowalik K, Cheng O, Bendiak G, Amin R, Dubeau A, Jensen R, Balkovec S, Gustafsson P, Ratjen F, Subbarao P (2018) Lung clearance index is elevated in young children with symptom-controlled asthma. Health Sci Rep 1(8):e58

8. Irving S, Fleming L, Ahmad F, Biggart E, Bingham Y, Cook J, Hall P, Jamalzadeh A, Nagakumar P, Bossley C, Gupta A, Macleod K, Saglani S, Bush A (2020) Lung clearance index and steroid response in pediatric severe asthma. Pediatr Pulmonol 55(4):890-898 
9. Miller MR, Hankinson J, Brusasco V, Burgos F, Casaburi R, Coates A et al (2005) Standardisation of spirometry. Eur Respir J 26(2):319-338

10. Robinson PD, Latzin P, Verbanck S, Hall GL, Horsley A, Gappa M, Thamrin C, Arets HGM, Aurora P, Fuchs SI, King GG, Lum S, Macleod K, Paiva M, Pillow JJ, Ranganathan S, Ratjen F, Singer F, Sonnappa S, Stocks J, Subbarao P, Thompson BR, Gustafsson PM (2013) Consensus statement for inert gas washout measurement using multiple- and single-breath tests. Eur Respir J 41(3):507-522

11. Anagnostopoulou P, Latzin P, Jensen R, Stahl M, Harper A, Yammine $S$ et al (2020) Normative data for multiple breath washout outcomes in school-aged Caucasian children. Eur Respir J
55(4). https://doi.org/10.1183/13993003.01302-2019 Print 2020 Apr

12. Lipworth B, Manoharan A, Anderson W (2014) Unlocking the quiet zone: the small airway asthma phenotype. Lancet Respir Med 2(6):497-506

13. Keen C, Olin A, Wennergren G, Gustafsson P (2011) Small airway function, exhaled $\mathrm{NO}$ and airway hyper-responsiveness in paediatric asthma. Respir Med 105(10):1476-1484

Publisher's note Springer Nature remains neutral with regard to jurisdictional claims in published maps and institutional affiliations. 